\title{
MEASUREMENT AND COMPARISON OF COSTS OF HYPERTENSIVE PATIENTS AGED 40-89 YEARS TREATED WITH LISINOPRIL AND PERINDOPRIL
}

\section{Joana I. Simeonova, Snejanka T. Tisheva- Gospodinova ${ }^{1}$, Yoana M. Todorova', Petkana A. Hristova, Asia N. Yanakieva ${ }^{1}$, Martin I. Hristov ${ }^{1}$}

Department of Pharmaceutical Sciences and Social Pharmacy, Medical University - Pleven, Bulgaria

${ }^{1}$ Department of Cardiology, Medical University - Pleven, Bulgaria

Corresponding Author:

Joana I. Simeonova

Department of Pharmaceutical Sciences and Social Pharmacy, Medical University - Pleven 1, St. Kl. Ohridski Str.

Pleven, 5800

Bulgaria

e-mail:goana@dir.bg

Received: June 15, 2017

Revision received: November 13, 2017

Accepted: February 27, 2018

\section{Summary}

A cross-sectional study was carried out in 2016 in the research project No 4/2016. We selected 98 patients aged 40-89 and diagnosed with hypertension. The patients were admitted to Cardiology Clinic One of the University Hospital in Pleven. The study aimed to measure and compare direct and indirect costs of hypertensive patients aged 40-89 years, who were treated with lisinopril and perindopril. We estimated the total and average costs of $50(51.0 \%)$ patients treated with lisinopril and $48(49.0 \%)$ treated with perindopril. Males were $46.4 \%$, and the mean age of the sample was $65.9 .0 \pm 11.2$ years. Data were processed by Statistical Package for Social Science version 19.0 (SPSS.v.19.0). Total costs exceeded amount reimbursed for the clinical path (BGN 420.00) in $64.6 \%$ of the patients treated with perindopril and $48.0 \%$ of the patients treated with lisinopril. We found that treatment costs within 6-months after discharge were BGN 673.82 in patients treated with lisinopril, as compared to BGN 171.92 reimbursed by the National Health Insurance Fund (NHIF), and BGN 781.18 for those treated with perindopril, compared to BGN 216.33 reimbursed by NHIF. The NHIF reimbursement rate for antihypertensive treatment is insufficient to cover all direct costs. Increased hospital costs and out-of-pocket payments present a significant restriction on access to treatment for arterial hypertension.

Key words: hypertension, lisinopril, perindopril, direct costs, indirect costs

\section{Introduction}

Hypertension is one of the most common diseases worldwide and a significant challenge for individuals, societies and health systems. The economic burden of hypertension for society is two-fold: first, the actual cost of the antihypertensive treatment, and second, the cost of managing the complications associated with uncontrolled hypertension.

The study aimed to measure and compare direct and indirect costs of hypertensive patients treated with lisinopril and perindopril.

\section{Patients and Methods}

\section{Design}

A cross-sectional study was carried out from May 
to November 2016. The study was part of project No 4/2016 "Economic assessment of antihypertensive therapy with lisinopril and perindopril by cost-effectiveness analysis and cost-utility analysis" and was approved by the commission on scientific and research ethics of MU - Pleven. All 98 patients aged 18 or older who met the inclusion criteria participated in the study (Table 1). They were admitted to the Cardiology Clinic One the University Hospital - Pleven. All the patients were diagnosed with arterial hypertension $(\mathrm{AH})$ in the clinical path (CP) No52 acute and subacute heart failure classes III-IV.

We followed up the patients six months after discharge and interviewed them by phone about drug use, blood pressure and drug-induced fatal and nonfatal cardiovascular diseases as well as costs due to ACE-inhibitor therapy. Some patients were not followed up after discharge because of missing or wrong contact information.

Table 1. Basic characteristics of the patients (Number, Mean, \%)

\begin{tabular}{llll}
\hline Variable & $\begin{array}{l}\text { Patients treated with lisinopril } \\
\text { Number (\%) }\end{array}$ & $\begin{array}{l}\text { Patients treated with perindopril } \\
\text { Number }(\%)\end{array}$ & Total \\
\hline Age & $66.2 \pm 11.2$ & $67.5 \pm 11.1$ & $66.0 \pm 11.0$ \\
\hline $40-49$ Yrs & $\mathbf{5}(10.6)$ & $\mathbf{5}(10.4)$ & $\mathbf{1 0}(10.5)$ \\
\hline $50-59$ Yrs & $\mathbf{1 3}(27.7)$ & $\mathbf{5}(10.4)$ & $\mathbf{1 8}(18.9)$ \\
\hline $60-69$ Yrs & $\mathbf{1 4}(29.8)$ & $\mathbf{1 6}(33.3)$ & $\mathbf{3 0}(31.6)$ \\
\hline $70-79$ Yrs & $\mathbf{1 0}(21.3)$ & $\mathbf{1 4}(29.2)$ & $\mathbf{2 4}(25.3)$ \\
\hline $80-89$ Yrs & $\mathbf{5}(10.6)$ & $\mathbf{8}(16.7)$ & $\mathbf{1 3}(13.7)$ \\
\hline Gender & & & $\mathbf{4 5}(46.4)$ \\
Males & $\mathbf{1 8}(36.0)$ & $\mathbf{2 7}(57.4)$ & $\mathbf{5 2}(53.6)$ \\
\hline Females & $\mathbf{3 2}(64.0)$ & $\mathbf{2 0}(42.6)$ & $\mathbf{9 8}(\mathbf{1 0 0 . 0})$ \\
\hline Total & $\mathbf{5 0}(\mathbf{5 1 . 0})$ & $\mathbf{4 8 ( 4 9 . 0 )}$ & \\
\hline
\end{tabular}

\section{Data}

Direct costs included all resources used in the process of the antihypertensive treatment. These were covered by the hospital, National Health Insurance Fund (NHIF) and the patients.

Information about actual hospital costs per treated patient based on CP No 52 was provided by Department of Medical Informatics and Statistics of the University Hospital - Pleven. CP No 52 reimbursement amounted to BGN 420 in 2016 [1].

We used retail prices of lisinopril and perindopril from the Positive drug list [2] to evaluate outpatient treatment costs (Table 2). We also included all outpatient drug-induced visits within six months after discharge from the hospital. In cases of fully-insured persons, we used reimbursement price per outpatient visit to a specialist, BGN 19.00 in 2016 [3]. In other cases, direct payments by the user occurred as out-of-pocket payments (OOPs) for specialist services without a GP referral on a fee-for- service basis by the price-list of the healthcare provider.

User charges to see a doctor (BGN 2.90) and hospital (BGN 5.40 per day of hospital stay up to 10 bed-days per year) were calculated and added to direct costs of the patient [4]. In the calculation of user charges, we took into consideration the reduced charges for retirees (BGN 1). The difference between the full and reduced charge (BGN 1.90) is covered by the Ministry of Health [5].

Patient time was the time that patient spent while seeking and receiving healthcare services and was calculated as the price of average income for extra working hours [6]. Minimum wage per hour was BGN 2.63 multiplied by $2=$ BGN 5.26.

Relatives' time for accompanying the patient to and from the hospital was calculated as a minimum salary per hour [6]. Relatives' time was calculated as BGN 2.63 in 2016.

Patients and relatives' travel expenses (by car, bus, train, etc.) to and from the hospital and 
Table 2. Costs for antihypertensive therapy with lisinopril and perindopril (Positive Drug List)

\begin{tabular}{llll}
\hline Drug & $\begin{array}{l}\text { Reimbursed level } \\
\mathbf{( 2 5 \% )} \text { by NHIF }\end{array}$ & $\begin{array}{l}\text { Co-insurance } \\
\mathbf{( 7 5 \% )} \text { by patient }\end{array}$ & Retail drug price \\
\hline Diroton 2.5 mg (28 tabl.) & BGN 0.22 & BGN 0.69 & BGN 3.84 \\
\hline Diroton 5 mg (28 tabl.) & BGN 0.45 & BGN 1.37 & BGN 3.58 \\
\hline Diroton 10 mg (28 tabl.) & BGN 0.91 & BGN 2.73 & BGN 5.05 \\
\hline Diroton 20 mg (28 tabl.) & BGN 1.82 & BGN 5.46 & BGN 9.10 \\
\hline Prestarium 5 mg (30 tabl.) & BGN 1.42 & BGN 4.26 & BGN 12.88 \\
\hline Prestarium 10 mg (30 tabl.) & BGN 2.84 & BGN 8.51 & BGN 15.16 \\
\hline
\end{tabular}

other health facilities were calculated and added to direct costs.

Three of the hypertensive patients were transported to the hospital by ambulance of the Center of Emergency Medical Care. These costs were calculated multiplying the distance travelled by the average fuel consumption (10 $1 / 100 \mathrm{~km})$ [7] and were covered by a transfer from the public budget [8].

Indirect costs included production losses. Since most of the participants in our study were retirement or illness pensioners, indirect costs were not measured.

\section{Statistical Analysis}

Data were processed by Statistical Package for Social Science versions 19.0 (SPSS.v.19.0). Number and percentage show distribution of the patients by gender and type of treatment. The average values in the distribution of age and costs are shown by mean and standard deviation (SD) for a symmetrical distribution or median (Mdn) - for an asymmetric distribution. We measured and compared total and average costs of the patients treated with lisinopril and perindopril.

\section{Results}

Ninety-eight patients participated in the study. The proportion of the patients by characteristics is presented in Table 1. Males were $45(46.4 \%)$, and their mean age was 65.9.0 \pm 11.2 years. The patients treated with lisinopril were $50(51.0 \%)$, and $48(49.0 \%)$ were those treated with perindopril.

\section{Total Hospital Costs}

We found that total hospital costs in all 98 patients treated on CP N0 52 amounted to BGN 41160.00. These costs exceeded the reimbursement price of the clinical pathway (BGN 420.00) in 56.1\% of all the cases (in $64.6 \%$ of the patients treated with perindopril and in $48.0 \%$ of the patients treated with lisinopril, respectively). Increased hospital costs in some patients treated with ACE-inhibitors were most likely due to more severe forms of the disease, requiring further examinations and more prescription drugs. On the other hand, NHIF does not reimburse costs of hospital provider in case of changes in therapy [9].

Actual hospital costs were higher for the patients treated with perindopril (BGN 29 982.22) as compared to the cost for the patients treated with lisinopril (BGN 22 658.49). Median direct costs per patient treated with perindopril were BGN 486.04 (Mdn, BGN 240.95-2874.66) and BGN 415.55 (Mdn, BGN 139.10-810.95) per patient treated with lisinopril (Table 3). The interval between minimum and maximum actual costs was higher in the patients treated with perindopril than in the patients treated with lisinopril. The difference between the two patient groups was due to higher direct costs in most patients treated with perindopril.

\section{Outpatient Costs}

Total costs of the patients for 6-month drug treatment after discharge with lisinopril were BGN 673.82 and BGN 781.18 - with perindopril. Median out-of-pocket monthly expenses per patient were BGN 5.7 for perindopril, as compared to BGN 4.3 for lisinopril (Figure 1). NHIF reimbursed BGN 216.33 of the costs for treatment with perindopril and BGN 171.92 with lisinopril for six months after discharge (Table 3). 
Table 3. Inpatient and outpatient costs for antihypertensive treatment in UMHAT - Pleven and within 6 months after discharge

\begin{tabular}{|c|c|c|c|c|c|c|}
\hline \multirow[t]{2}{*}{ Costs } & \multicolumn{3}{|c|}{ Lisinopril } & \multicolumn{3}{|c|}{ Perindopril } \\
\hline & 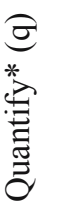 & 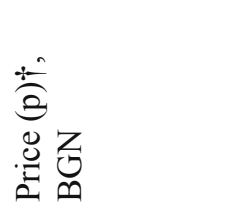 & 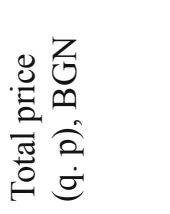 & 昰 & 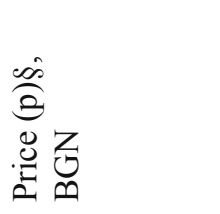 & 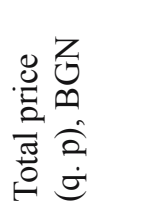 \\
\hline Hospital & 50 & $\begin{array}{l}415.55(\mathrm{Mdn}, \\
139.10- \\
810.95)\end{array}$ & 22658.49 & 48 & $\begin{array}{l}486.04(\mathrm{Mdn}, \\
240.95- \\
2874.66)\end{array}$ & 29982.22 \\
\hline $\begin{array}{l}\text { (Including: } \\
\text { Reimbursement price per patient based on } \\
\text { CP N052) }\end{array}$ & 50 & 420.00 & 21000.00 & 48 & 420.00 & 20160.00 \\
\hline $\begin{array}{l}\text { Hospital costs exceeding CP N052 } \\
\text { reimbursement price }\end{array}$ & & & 1658.49 & & & 9822.22 \\
\hline \multicolumn{7}{|l|}{ Patients } \\
\hline \multicolumn{7}{|l|}{ Costs, including: } \\
\hline $\begin{array}{l}\text { - co-insurance of lisinopril/perindopril } \\
\text { after discharge from the hospital or full } \\
\text { drug price OOPs in the pharmacy }\end{array}$ & 28 & & 673.82 & 23 & & 781.18 \\
\hline $\begin{array}{l}\text { - } \quad \text { travelling expenses (car, bus, train, etc.) } \\
\text { to and from the hospital and ambulatory }\end{array}$ & 49 & & 871.06 & 44 & & 943.66 \\
\hline - $\quad$ patients` time & 50 & 5.26 & 416.54 & 48 & 5.26 & 394.50 \\
\hline $\begin{array}{l}\text { - } \quad \text { user charge for visit to physician, } \\
\text { including retirees }\end{array}$ & $\begin{array}{l}2 \\
2\end{array}$ & $\begin{array}{l}2.90 \\
1.00\end{array}$ & $\begin{array}{l}5.80 \\
2.00\end{array}$ & & & \\
\hline - $\quad$ user charge per day of hospitalization & 5 & $\begin{array}{l}5.40 \times 25 \\
\text { bed-days }\end{array}$ & 135.00 & 1 & $\begin{array}{l}5.40 \times 3 \text { bed- } \\
\text { days }\end{array}$ & 16.20 \\
\hline - $\quad$ OOPs (fee-for-service) & 1 & 20.00 & 20.00 & & & \\
\hline \multicolumn{7}{|l|}{ Relatives } \\
\hline \multicolumn{7}{|l|}{ Costs, including: } \\
\hline $\begin{array}{l}\text { travelling expenses (car, bus, train, } \\
\text { etc.) to and from the hospital }\end{array}$ & 19 & & 277.12 & 14 & & 202.30 \\
\hline - $\quad$ relatives time & 25 & 2.63 & & 24 & 2.63 & 65.12 \\
\hline \multicolumn{7}{|l|}{ NHIF } \\
\hline \multicolumn{7}{|l|}{ Costs, including: } \\
\hline $\begin{array}{ll}\text { - } & \text { price of lisinopril/perindopril } \\
\text { reimbursed by NHIF }\end{array}$ & 25 & & 171.92 & 22 & & 216.33 \\
\hline - $\quad$ outpatient follow-up visits & 5 & 19.00 & 95.00 & 2 & 19.00 & 38.00 \\
\hline \multicolumn{7}{|l|}{ Ministry of health } \\
\hline \multicolumn{7}{|l|}{ Costs, including: } \\
\hline $\begin{array}{l}\text { - } \text { difference between the full and the } \\
\text { reduced user charge in retirees }\end{array}$ & 2 & 1.90 & 3.80 & & & \\
\hline $\begin{array}{l}\text { - ambulance costs in emergency cases }(10 \\
1 / 100 \mathrm{~km})\end{array}$ & 1 & & 2.06 & 2 & & 41.37 \\
\hline Total costs & & & 25398.36 & & & 32680.88 \\
\hline
\end{tabular}




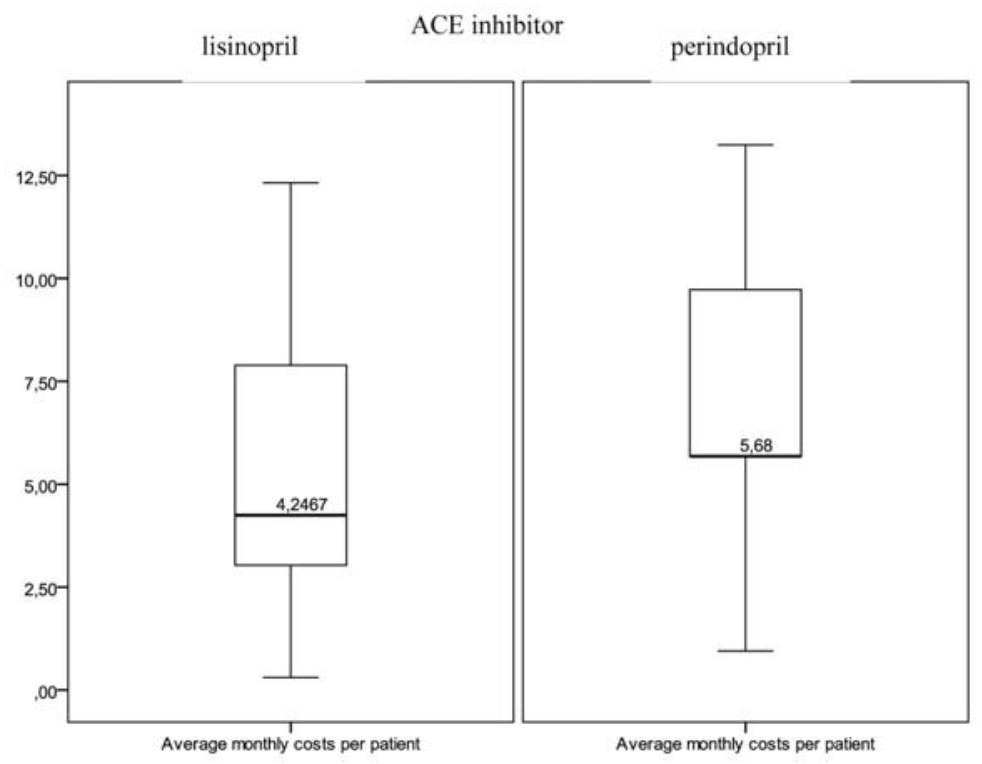

Figure 1. Median monthly out-of-pocket expenses of hypertensive patients treated with lisinopril and perindopril in BGN

Total patients travel expenses (by car, bus, train, etc.) to and from health facilities were higher for patients treated with perindopril (BGN 943.66) than for those treated with lisinopril (BGN 871.06). Patients treated with perindopril paid an average of BGN 15.00 per month, as compared to patients on lisinopril paid BGN 14.00 (Table 3).

Travel expenses for relatives to accompany patients treated with lisinopril to and from health facilities amounted to a total of BGN 277.12. Such expenses associated with patients treated with perindopril were BGN 202.30.

Most of the patients in the study were exempt from hospital stay charges because they had chronic diseases included in a list appended to National Framework Contract [3]. Cost sharing in the patients treated with lisinopril per visit to a physician was BGN 5.80. User charges for a visit to the hospital were BGN 135.00 for the patients treated with lisinopril, and BGN 16.20 for the patients treated with perindopril.

The hospital stay of those treated with lisinopril cost more - BGN 416.54 than that of patients treated with perindopril (BGN 394.50).

Relatives' time spent to accompany a patient to and from the hospital cost BGN 65.75 for patients treated with lisinopril, and BGN 65.12 for those treated with perindopril.

Total costs were higher in the patients treated with perindopril (BGN 32 680.88, BGN 507.97 per patient) than in the patients treated with lisinopril (BGN 25 398.36, BGN 680.86 per patient).

\section{Discussion}

Hypertension is among the most prevalent worldwide diseases and a major challenge for individuals, society and health systems for many reasons [10]. Worldwide, the prevalence of hypertension exceeds $40 \%$. Nearly one of every three Bulgarian adults aged 25-64 has a high blood pressure, respectively $42.8 \%$ males and $39.7 \%$ females. This prevalence increases with age - from $6.6 \%$ in age group $25-34$ to $58.3 \%$ in individuals over 65 years of age [10]. Recent statistics have shown an adverse trend of hypertension among the young population [11, 12].

Most hypertensive patients have failed to achieve blood pressure levels lower than 140/90 $\mathrm{mm} \mathrm{Hg} \mathrm{[10-14].} \mathrm{The} \mathrm{proportion} \mathrm{of}$ well-controlled hypertension among the treated hypertensive patients in Bulgaria was smaller (6-10\%), as compared with $27 \%$ for other eight countries in Central and Eastern Europe [15].

Only one-fourth of the patients with hypertension in Bulgaria are on the same drug treatment for a year. More than $35 \%$ of the hypertensive patients discontinued medication, commonly during the first month, and the price is a significant reason $[16,17]$. In general, drug treatment costs were reimbursed partially (25- 
$50 \%$ ) by NHIF, and reimbursement is higher for combined antihypertensive therapy than for monotherapy. Patient cost sharing for the two antihypertensive drugs was BGN 903.00 in 2014 [17-19]. Almost one-third of the costs for antihypertensives are related to the discontinuation of the initial drug therapy, and another $20 \%$ are due to changes in the treatment [20].

We found that the average out-of-pocket monthly expenses per patient treated with perindopril were BGN 5.7 and BGN 4.3 for lisinopril. Similar results were reported by $\mathrm{T}$. Vekov (2009) [17]. Monthly costs for ACE inhibitor treatment per patient varied in the range of $\$ 10-100$ in the USA, but when the patient was included to Medicare using generic drugs, costs decreased to $\$ 4$ per month [2122]. One limitation of drug treatment for hypertension in Bulgaria is the lower number of ACE inhibitors prescriptions to patients and high-dose monotherapy, as compared to the USA and Western European countries [17, 21, 23]. Monotherapy is effective in $25-40 \%$ of the hypertensive patients, while and $60-75 \%$ need combined antihypertensive therapy [15].

Monthly costs for drug treatment of hypertension combined with ischemic heart disease per patient were BGN 61.85 and BGN 120.60 - for hypertension combined with heart failure. Patient cost-sharing was almost $75 \%$ [17]. In fact, most of the patients included in this study took more medications in addition to ACE-inhibitors, although these costs were not added to patient cost sharing for drug treatment outside the hospital. Thereby, we could calculate precisely the costs related to drug treatment of hypertension, but it was impossible to measure a net effect of drugs on newly diagnosed diseases. Moreover, actual patients' out-of-pocket expenses for complex drug treatment per month in our hypertensive patients would be much higher than the cost sharing for ACE inhibitors. Monthly costs for monotherapy per patient were BGN 10.14 in 2008, BGN 18.64 for a doubledrug combination, and BGN 54.41 - for a tripledrug combination. Similar results were reported by Ivanova and Petrova (2009) [24]. Moreira et al. (2009) [25] reported monthly medication costs of $\$ 87.10$ for monotherapy, $\$ 159.00$ for treatment with two drugs, and $\$ 294.00$ for combined treatment with three or more drugs.

Some researchers have calculated annual drug treatment costs for hypertension amounting to \$392.76 per patient in Brazil [26]. Krzysztoszek et al. (2014) [27] reported similar results and costs were increased two-fold due to the presence (\$723.46) or absence (\$342.15) of comorbidity. Total costs of the patients in the present study for six-month treatment with perindopril were BGN 107.36 higher than that with lisinopril. Heidenreich et al. (2008) [28] compared additional drug costs in patients treated with lisinopril and amlodipine versus chlortalidone and reported higher costs for lisinopril than for amlodipine.

Hypertension ranks second among diseases in Bulgaria with costs over $70 \%$ of the NHIF budget for drugs and medical products in outpatient healthcare. NHIF costs for drug treatment outside the hospital for the first six months of 2013 were BGN 30815911 (11.2\% of the total drug treatment costs) compared to BGN 21338952 or $12.2 \%$ for the second 6 months of 2013 [17-19]. According to that study, the total costs of NHIF for drug treatment on an outpatient with ACE inhibitors for six months were BGN 388.25 (BGN 171.92+216.33).

Direct costs were BGN 7637.47 higher for the patients treated with perindopril than for the patients treated with lisinopril. Hospitalization costs were the primary component of direct costs in that study, although these costs came second in the survey of Krzysztoszek et al. (2014) [27]. Lee et al. (1997) [23] reported that the total drug costs in a hypertension clinic during a sevenweek study period were $£ 21510$, and prices of ACE inhibitors were disproportionately higher and considerably increased the treatment cost. A study by Azarisman et al. (2009) [29] confirmed that costs of ACE inhibitors were high, especially for perindopril (RM 320539.53 or $14.5 \%$ of total drug costs). However, the full median price per month in elderly hypertensive patients was higher for older ACE inhibitors than newer ones [25]. Hospitalization costs increased with poorer adherence to and persistence with antihypertensive therapy [30, 31].

Greater compliance with antihypertensive therapy has been shown to be associated with lower costs for physicians. Rizzo et al. (1996) [31] reported that a person with uncontrolled 
hypertension loses 5.5 workdays per year and that 3.5 of the disability days could be avoided if treatment adherence was optimized. We found that patient time-costs were BGN 416.54 for treatment with lisinopril, as compared to BGN 394.50 for that with perindopril.

All the 44 studied patients treated with perindopril paid BGN 943.66 for travelling expenses, and these costs were the essential component of the direct non-medical costs compared to Krzysztoszek et al. (2014) [27]. Forty-nine of our patients treated with lisinopril paid for travelling expenses less than the 44 patients treated with perindopril.

The total costs for 6-months pharmacotherapy in patients treated with lisinopril was BGN 7283 cheaper than perindopril. Direct non-medical costs per patient were BGN 172.89 lower in lisinopril than perindopril. These results were inconsistent, compared to Heidenreich et al. (2008) [28] who reported higher direct and indirect costs in patients treated with lisinopril.

Many studies have reported cost-saving for society by lowering blood pressure, especially in patients with cardiovascular disease $(\$ 1230$ per patient in men and $\$ 650$ in women) or second-stage hypertension (\$600 per patient in men) [13]. Annual changes in the treatment costs by clinical guideline implementation for hypertension amounted from $-£ 2491$ in the first year to $-£ 15653$ in the fifth year [32]. Effective treatment and management for achieving blood pressure target levels could save $€ 1.26$ billion for health insurance fund systems [10].

\section{Conclusions}

Total direct treatment costs are lower in patients treated with lisinopril than in patients treated with perindopril.

The NHIF reimbursement level for antihypertensive treatment is insufficient to cover all direct costs. Increased hospital costs and out-of-pocket payments are a barrier to accessing treatment for arterial hypertension.

\section{Acknowledgements}

This study was part of project No 4/2016 "Economic assessment of antihypertensive therapy with lisinopril and perindopril by cost- effectiveness analysis and cost-utility analysis". The study was funded by Medical University - Pleven. This publication was supported by project No BG05M2OP001-2.009-0031-C01.

\section{References}

1. Ordinance No 04-07-1 of Mar, 29, 2016 for correction and in addition to Ordinance N0 0424-1: Published by Ministry of Health. State Gazette. 2016 Mar, 25.

2. National Council on Prices and Reimbursement of Medical Products. Positive Drug List 2017 [Internet]. Sofia 2017 [cited 2017 June 16]. Available from: http://www.ncpr.bg/bg/

3. Ministry of Health. [National Framework Contract between NHIF and BMA - 2015]. State Gazette Issue 25 as of March 31, 2016. Bulgarian

4. Government Decree No 193 of Aug, 28, 2012. Published by Council of Minister of the Republic in Bulgaria. State Gazette.2012 Sept, 4

5. Government Decree No 312 of Dec, 27, 2013 for correction and in addition to Government Decree N0 193 of Aug, 28, 2012. Published by Council of Minister of the Republic in Bulgaria. State Gazette. 2014 Jan, 7.

6. Drummond M, O' Brien BJ, Stoddart G, Torrance GW. Methods for the Economic Evaluation of Health Care Programmes. $3^{\text {rd }}$ ed. Oxford: University Press, 2005.

7. Center of Emergency Medical Care - Pleven. [Specification of ambulance]. p. 3. Bulgarian.

8. Ministry of Health of the Republic of Bulgaria. [Concept "Objective for Health 2020"], Sofia; 2015. Bulgarian

9. [Payment methods of health services in hospital care.] Published by Council of Minister of the Republic in Bulgaria. State Gazette, 2015 Mar, 20. Bulgarian.

10. Hansson L, Lloyd A, Anderson P, Kopp Z. Excess morbidity and cost of failure to achieve targets for blood pressure control in Europe. Blood Press. 2002;11(1):35-45.

11. Bulgarian Society of Internal Medicine. [National Association of general practitioners in Bulgaria, Bulgarian Hypertension league. Guideline of the Management of the Arterial hypertension for general practitioners]. Sofia: National Association of general practitioners in Bulgaria; 2007. Bulgarian

12. Marinov L. [Arterial hypertension and salt intake]. Science Cardiology 2009;3:100-102. Bulgarian

13. Moran A, Odden M, Thanataveerat A, Tzong $\mathrm{K}$, Rasmussen $\mathrm{P}$, et al. Cost-effectiveness of 
Hypertension Therapy According to 2014 Guidelines. N Engl J Med. 2015;372(17):1677.

14. Naser N, Dzubur A, Durak A, Kulic M, Naser N. Blood Pressure Control in Hypertensive Patients, Cardiovascular Risk Profile and the Prevalence of Masked Uncontrolled Hypertension (MUCH). Med Arch. 2016;70(4):274-9.

15. Torbova S, Gocheva N, Sirakova V, Tarnovska R, Donova T, Vlahov V. [Consensus of monotherapy and combination therapy of patients with Arterial Hypertension in Bulgaria]. Bulgarian Cardiology 2005;5(11), 1-31. Bulgarian.

16. Georgiev B, Genov A, Baitcheva V, Kostova E. [Combination therapy in essential hypertension: contemporary approach to combine calcium antagonists and beta-blockers]. Science Cardiology 2014;15(5):231-239. Bulgarian.

17. Vekov T. [Stimulation of generic drugs prescription - the shortest way to cut public and personal costs for medical products]. General medicine journal 2009;11(3):14-16. Bulgarian.

18. Raev D, Barkalova D. Initial antihypertensive therapy in Bulgaria. A National prospective, observational study (BP-Initial Therapy-BG study). Journal of Hypertension. 2015;33 Suppl 1.

19. Vekov T. [Analysis of reimbursement expenditures of the National Health Insurance Fund for medical products for home therapy]. General medicine journal 2012;14(3):23-29. Bulgarian.

20. Gocheva N. [Initial therapy of arterial hypertension by combined drug with low dosage]. Science Cardiology 2005; 3:100-104. Bulgarian.

21. Bian B, Kelton C, Guo J, Wigle P. ACE Inhibitor and ARB Utilization and Expenditures in the Medicaid Fee-For-Service Program from 1991 to 2008. J Manag Care Pharm. 2010;16(9):6719.

22. Consumer Report Health. Using ACE inhibitors to treat: High Blood Pressure and Hearth Disease - Companying Effectiveness, Safety and Price, $19 \mathrm{p}$.

23. Lee , Robin K, Chan J, Chang S, Lee SC, Tomlinson B. A prescription survey in a hospital hypertension outpatient clinic. $\mathrm{Br} \mathrm{J}$ Clin Pharmacol. 1997;44:577-2.

24. Ivanova A, Petrova G. Hypertension and common complications - analysis of the ambulatory treatment cost. Cent Eur J Public Health. 2009;17(4):223-0.

25. Moreira GC, Cipullo JP, Martin JF. Evaluation of the awareness, control and cost-effectiveness of hypertension treatment in a Brazilian city: populational study. J Hypertens. 2009;27:19007.

26. Dias da Costa JS, Fuchs SC, Olinto MT. Costeffectiveness of hypertension treatment: a population-based study. Sao Paulo Med J. 2002;120(4):100-4.

27. Krzysztoszek J, Koligat D, Ratajczak P, Bryl W, Cymerys M, Hoffmann K, et al. Piotr Ratajczak1, Wiesław. Economic aspects of hypertension treatment in Poland. Arch Med Sci. 2014;10(3):607-7.

28. Heidenreich PA, Davis BR, Cutler JA. Costeffectiveness of chlorthalidone, amlodipine, and lisinopril as first-step treatment for patients with hypertension: an analysis of the Antihypertensive and Lipid-Lowering Treatment to Prevent Heart Attack Trial (ALLHAT). J Gen Intern Med. 2008; 23(5):509-6.

29. Azarisman SMS, Aszrin A, Sahimi M, Ngow HA, Marzuki AO, Jamalludin AR, et al. Evaluation of antihypertensive drug utilization and cost in Hospital Tengku Ampuan Afzan, Kuantan. IMJ. 2009;8(2):29-35.

30. Small RE, Freeman-Arnold SB, Goode JV, Pyles MA. Evaluation of the total cost of treating elderly hypertensive patients with ACE inhibitors: a comparison of older and newer agents. Pharmacotherapy. 1997;17(5):1011-6.

31. Rizzo JA, Abbott TA, III, Pashko S. Labour productivity effects of prescribed medicines for chronically ill workers. Health Econ. 1996;5(3):249-5.

32. National Institute for Health and Clinical Excellence. Hypertension: Cost Report Implementing NICE Guidance 2011. London: NICE Midcity Place; 2011. 